\title{
INCITACIONES LESBIANAS EN \\ "MILAGROS, CALLE MERCURIO" DE CARMEN LUGO FILIPPI
}

\author{
POR \\ LUZ MARÍA UMPIERRE \\ Western Kentucky University
}

Como lectora de literatura puertorriqueña, aún no he encontrado un texto narrativo escrito por una mujer que trate abiertamente el tema del lesbianismo. ${ }^{1}$ Con frecuencia me he puesto a pensar sobre los motivos de esta falta y el principal, que siempre me viene a la mente, es el del miedo que pueda tener la escritora de que la cataloguen a ella de lesbiana si escribe dicho texto narrativo, y las consecuencias que tendría que afrontar por parte de la historia y la crítica literaria heterosexista puertorriqueña y de la misma sociedad.

Como lectores, tenemos la tendencia de buscar obras que de alguna forma ratifiquen algunas de las percepciones que tenemos sobre la vida y nuestras experiencias y obras que abran nuevas puertas a la imaginación y al intelecto. Al quedar en el vacío por la falta de textos narrativos que representen personajes, situaciones, problemas o intereses lesbianos en la literatura puertorriqueña y no estar muy propensa a asumir una postura "existencialista" al respecto -i.e. "Estoy sola sin textos lesbianos en el mundo de las letras puertorriqueñas" - me he propuesto llenar este vacío leyendo la narrativa de la isla, sobre todo después de 1970, con una perspectiva que califico de homocrítica. El leer desde esta perspectiva implica el sacar del armario ("closet") crítico las percepciones que tengo como lectora y el modo en que enfoco los textos, para parafrasear una serie de TV: EN BUSCA DE ... Esta búsqueda de textos que narren relaciones estrechas entre mujeres no ha sido del todo infructuosa y he descubierto algunas obras que describen este tipo de relaciones.

Algunos de los cuentos de Rosario Ferré, por ejemplo, probablemente ganen un primer premio en mi certamen de cuentos semejantes a lesbianos, ya que ella

1 Es muy interesante que haya, no obstante, varios relatos sobre homosexualidad masculina escritos por mujeres: "De tu lado al paraíso" de Rosario Ferré, y "Halloween en Leonardo's" de Mayra Montero. Conozco asimismo la colección de poemas Primavida de Anita Vélez, que trata el tema de mujeres unidas a otras mujeres. Conozco también una obra de teatro escrita por un hombre en Puerto Rico sobre el tema del lesbianismo, la cual fue protagonizada por Lydia Echevarria. En estos momentos no tengo información más detallada sobre la obra. 
ha creado varios cuentos en que se representan estrechas relaciones positivas entre mujeres. Entre ellos se encuentra "Pico Rico Mandorico" que, en mi opinión, es con el que más se ha acercado a escribir un cuento con personajes lesbianos.

Lo que he notado también, y ahora me refiero a mí misma como lectora y como lesbiana, es que en ciertos textos se crea una sensación de incitación en la lectora por medio de narraciones que presentan una estrecha relación entre mujeres. El hecho de que estos cuentos no representen estas relaciones como lesbianas y que las escritoras de éstos no quieran admitir el uso de temas lesbianos hace que a veces me pregunte a mí misma como crítica: ¿Soy una perturbada sexual que lee estos textos como si estuviera mirando por el ojo de una cerradura o estos textos presentan realmente un material que me incita como lesbiana y los leo desde un punto de vista homocrítico?

En uno de los mejores artículos que he leído sobre lecturas lesbianas, "Ourself behind Ourself: A Theory for Lesbian Readers", Jean Kennard sugiere un método, al cual le da el nombre de lectura polar" para "lectoras lesbianas y otras cuyas experiencias no se reflejan con frecuencia en la literatura" (traducción mía). ${ }^{2}$ Añade asimismo que "la lectura polar permite la participación de cualquier lectora en cualquier texto ... Sin embargo, no hace que la lectora se niegue a sí misma. La lectora se redefine a sí misma en oposición al texto: si esa auto-definición incluye el lesbianismo, esto se refleja en cualquier comentario que ella haga sobre la lectura ${ }^{\prime}{ }^{3}$ La sugerencia de Kennard resulta interesante; no obstante, su estrategia se limita precisamente al reino de la lectora y no hace mención alguna al otro polo: ciertos textos que son escritos como incitaciones para una lectora lesbiana. ${ }^{4}$

En un artículo sobre personajes femeninos en la narrativa contemporánea puertorriqueña, Magali García Ramis menciona entre otras cosas que lo que une a las obras de este grupo de escritoras es el uso de la ironía para criticar cómo las mujeres, para llevar una vida tranquila en la sociedad puertorriqueña, han tenido que adherirse a situaciones sociales, políticas y culturales arcaicas, injustas e injustificables. ${ }^{5}$ Ella se refiere en su artículo a las obras de Rosario

2 Jean E. Kennard, "Ourself behind Ourself: A Theory for Lesbian Readers", Gender and Reading: Essayson Readers, Texts and Contexts, editado por Elizabeth A.Flynn y Patronicio P. Schweickart (Baltimore: John Hopkins University Press, 1986) 77. El artículo de Kennard abarca mucho más que el renombrado "Zero Degree Deviancy: The Lesbian Novel in English", de Catharine R. Stimpson. Critical Inquiry (Winter, 1981) 363-379.

${ }^{3}$ Kennard, 77.

4 Quiero aclarar parte de mi terminología. Una lectura homocrítica es la que hace una lectora lesbiana de un texto siguiendo o viendo la homosexualidad en él.

- Magali García Ramis, "Para que un día Luz María pueda comprar los zapatos que le dé la gana", Caribán 5-6 (1985) 6 y 30-31. 
Ferré, Ana Lydia Vega y Carmen Lugo Filippi, y a la forma en que estos cuentos tratan de manera negativa a algunos personajes femeninos, lo cual García Ramis estima que tiene sus raíces en la estructura de la vida puertorriqueña. Al leer su artículo, me llamaron la atención las líneas que dedicó al cuento de Carmen Lugo Filippi, "Milagros, calle Mercurio". García Ramis dice que el personaje principal del cuento, Milagros, aparentemente se libera de su madre y de la religión convirtiéndose en una prostituta y que esta liberación la convierte, inevitablemente, en una esclava.

Admito que me inquieté al leer estas líneas, ya que en 1983 analicé este mismo cuento desde una perspectiva diferente en un curso a nivel subgraduado de literatura caribeña. Yo enfoqué en aquel entonces la obsesión de la narradora Marina con Milagros, una adolescente. Desde mi punto de vista, Marina era el personaje principal y yo había interpretado el final del cuento como la realización de una de las fantasías de Marina con Milagros -el corte simbólico de su pelo. Admito que hubo un estudiante puertorriqueño en mi clase que disputó con enojo mi lectura, pero varias estudiantes ayudaron a realzar $\mathrm{mi}$ interpretación admitiendo que ellas también habían tenido una experiencia 'interesante' al tratar con Marina como narradora.

Volviendo al artículo de García Ramis, al leerlo me pregunté a mí misma si me incliné sobre el cuento, siguiendo la sugerencia de Kennard, haciendo una lectura polar', o si había codificado en el cuento un motivo lesbiano que me incitara a una lectura homocrítica. Decidí re-leer el cuento, pero esta vez dudando tanto de la lectura de García Ramis como de la mía propia.

En esta nueva lectura, me di cuenta de que lo primero que llamó la atención al leer el cuento originalmente fue la narración en primera persona y el hecho de que Marina, la narradora, fuera una estudiante que no terminó sus estudios universitarios de literatura comparada después de tres años. El hecho de que fuera una peluquera ahora y que narrara este cuento como si se lo estuviera contando a una cliente, me atrajo más al texto por varios motivos. Mi peluquera en Puerto Rico siempre me está haciendo cuentos de su vida y de la de otros mientras me arregla el pelo. De modo que Marina, la peluquera, cabía bien dentro de mi estructura referencial, y el hecho de que hubiera estudiado literatura cerró la brecha entre lo que se narraba y yo. No obstante, a la vez que estas cosas me atraían al texto, algo en Marina misma me alejaba - susínfulas de grandeza. Marina admitió que estaba dispuesta a desinflar el ego de cualquier mujer que se le parara al frente. Esta tensión de "estira y encoje" la mantuve durante la lectura del texto hasta que apareció Milagros.

Marina había hablado tanto del desdeño que sentía hacia otras mujeres a las que había calificado de "perfectos monigotes con ínfulas de grandes damas"6 (una afirmación que me parece una proyección suya más que otra cosa), que la

- Carmen Lugo Filippi, "Milagros, Calle Mercurio", Apalabramiento, Efrain Barradas, editor (New Hampshire: Ediciones del Norte, 1983) 204. 
aparición de una mujer de quien ella dice: "La recuerdo tan vivamente" (205), el detalle con que describe a Milagros, la atención con la cual Marina la sigue y la obvia atracción que siente al verla aparecer, todo eso me atrajo hacia el cuento. Ahora ya, en esta nueva lectura homocrítica, era obvio para mí de nuevo que Marina era el personaje principal del cuento y descarté las dudas que me trajo la interpretación de García Ramis sobre Milagros. Pero aún me quedaba en la mente el hecho de que García Ramis hubiera hecho una omisión total de Marina y hubiera visto el final del cuento comoel lanzamiento de Milagros hacia la prostitución. Me pregunté a mí misma: ¿por qué en su lista de personajes femeninos de la ficción puertorriqueña contemporánea, García Ramis había preferido descalificar, anular, omitir a Marina?.

La respuesta a esta pregunta se me hizo más evidente a medida que progresaba en mi nueva lectura del cuento. García Ramis, siendo una mujer que se dedica a la crítica de la literatura puertorriqueña y escritora además, debe haber leído el cuento, sin lugar a dudas, observando el cambio de Milagros de ser una joven aparentemente buena, obediente y respetuosa, leal a su madre y a la iglesia Pentecostal, a convertirse en una mujer que se desnuda lentamente en un bar local delante de unos viejos verdes. No voy a mencionar mis objeciones con respecto a la forma de ver el cambio de Milagros, de virgen a prostituta. Eso me desviaría del tema de la lectura y me llevaría al de la caracterización - de eso trataré en otro trabajo. Comentaré, no obstante, que esta interpretación en particular del cambio en Milagros se ajusta al patrón tradicional dentro de la crítica literaria puertorriqueña y a los puntos de vista sobre/de las mujeres: prevalece tanto la dicotomía de virgen/prostituta en el análisis de los textos que los limitan a este solo contraste. Por otra parte, al contrario de García Ramis, yo no vivía en la isla y me hallaba separada de la vida diaria allí. Yo estaba a la distancia; yo podía permitirme el aceptar las incitaciones del texto de Lugo Filippi. Yo podía escuchar el relato de Marina. Unos cuantos ejemplos del discurso de Marina y el uso de una técnica narrativa me ayudarán a ilustrar el relato que escuché de Marina.

En su descripción de Milagros y su primera reacción hacia ella, Marina admite: "contemplarla suscitaba en mí un extraño fenómeno de correspondencias" (206). Dado el caso de que Marina se atreve a confesar cierta atracción hacia Milagros, otra voz aparece ahora en el texto, una que trata a Marina de "tú" mientras describe las fantasías que Marina tiene del pelo de Milagros. Esta voz, la cual quiero describir como la voz de la fantasía, se convierte entonces en la voz narradora por varias páginas en las que hay algunas descripciones de otras fantasías de Marina - conversaciones imaginarias con Milagros y la persecución verdadera de Marina a Milagros. El hecho de que el cuento cambiara a esta voz narradora, que hacía que las fantasías de Marina salieran a la luz, fue crucial para mí como lectora e hizo que me interesara más en el texto. Pero yo era una lectora lesbiana. ¿Qué hubiera pasado si yo hubiera sido García Ramis o una de las mujeres heterosexuales de la isla que se dedican a la critica literaria? Algunas de mis estudiantes han respondido de forma parcial a esta pregunta. 
Ellas han visto estos pasajes como una indicación de una 'enfermedad' de Marina, de un defecto, de algo enfermizo, afirmaciones éstas que yo he debatido de inmediato como heterosexismo. Pero las estudiantes que pensaban de esta forma no tenfan la menor duda de que Marina era el personaje principal - ellas estaban, como yo, a cientos de millas de distancia de la isla.

Volviendo al texto, después de estas páginas de la segunda voz que "revelan" (lectura lesbiana) o "perturban" (lectura heterosexista), la narración vuelve de nuevo a la voz narradora en primera persona. No es sorprendente entonces que la voz de Marina "encerrada en el closet", el "yo" que obra frente a otros, vuelva en estos momentos a hacer declaraciones negativas acerca de las mujeres como las que veíamos al principio del cuento. Ella ahora llama a Milagros "madonita" y pregunta: "¿Sería una retrasada mental con aires de modelo sanjuanera?" (209). Volví a sentir la sensación de "estira y encoje" ante el texto. Marina y su relato nos tendían trampas. Cuando la parte del cuento que trata de las fantasías de Marina me resultaba "reveladora" como lesbiana, aunque quizás "perturbadora" para una persona heterosexual, el cuento, como diríamos en PuertoRico: "recobraba compostura" - compostura social. Marina, por lo tanto, tenía que volver a su postura hacia las mujeres - tenía que rechazarlas.

Pero su compostura dura poco porque aparece una chismosa con la noticia de que Milagros ha estado manteniendo una doble vida: "aleluya" por el día (virgen)/ "guayanilla" por la noche (prostituta). Milagros ha sido vista en un bar en Guayanilla trabajando de artista, desnudándose lentamente ante los hombres.

Aparece aquí de nuevo la voz de la 'fantasía' en la segunda persona para suplantar el "yo" de Marina. Marina está a punto de visualizar en su mente a Milagros desnudándose lentamente y excitarse al pensarlo. Esto es un tabú. Marina es un personaje femenino de la literatura puertorriqueña. ¿Cómo se le puede permitir que erotice a Milagros con tanto detalle? Por eso es que entra en juego otro elemento interesante: Marina se convierte en un hombre en su fantasía - o sea Rada, el oficial de la policía que llaman a la escena del desnudo. $Y$ en ese momento se presenta una verdadera caja china ante nuestros ojos: la segunda voz narra lo que Marina imaginó que vió a través de los ojos de Rada:

La masa lechosa inicia su sensual contoneo, mientras el estribillo pegajoso de la melodía se impone. Esta vez la luz indiscreta persigue los convulsivos movimientos y el Rada entonces se excita viendo cómo la serpentosa figura se yergue de espaldas y muestra con estudiada morosidad dos perfectas redondeces que contrastan con la llana geografía del suave torso ... Los jadeos parecen haber cesado bajo el influjo de ese momento perfecto ... Y ahí está Milagros, ante los asombrados ojos del Rada, quien parpadea incrédulo, quien se frota los ojos para despertar y ver siempre aquellos muslos lechosos, adornados por un montoncito de pelo lleno de pizpiretos miosotis ... el Rada no despega sus ojos de los menudos senos que comienzan a flotar y sólo el estruendoso platillazo final lo devuelve a la realidad (214-215). 
Dada la elevada carga sexual de la descripción, ha aparecido una doble puerta del closet para "salvar" la situación. Dentro de la sociedad puertorriqueña a Rada se le permite disfrutary excitarse con el baile erótico de Milagros; a Marina no. No obstante, la escena no deja de estar cargada de sexualidad. En mi opinión, este truco del texto es crucial en lo que respecta a la interpretación "tradicional" de García Ramis en cuanto a la conversión de Milagros en prostituta. Después de todo, Rada es quien ve el desnudo, aparentemente, y eso ocurre en un bar de hombres. En mí lectura homocrítica, sin embargo, Milagros hace su actuación del desnudo para Marina, pero para hacer mención de esto, el texto ha establecido una doble distancia mediante la segunda voz narrativa donde Marina crea la fantasía de lo que ve Rada. La tensión de "estira y encoje" se ha vuelto ahora más compleja. Resulta obvio para mí, como lectora lesbiana, que Marina se ha excitado por el aspecto y el cuerpo de Milagros desde el momento en que la conoció. No obstante, teniendo en cuenta lo que he mencionado anteriormente con respecto a las escritoras puertorriqueñas y los temas lesbianos, esta parte principal del cuento se tiene que revestir ahora con varias capas de azúcar para que sea aceptable a la vez que se deja abierta una salida "adecuada". Yo creo que el texto presenta juegos de atracción "directa" conmigo como lectora lesbiana - juegos de "ven y tómame", lee mi cuento, el relato de Marina-y juegos de "rechazo" - la intervención de la segunda voz y el distanciamiento usando la fantasía' de Rada: juegos de negación.

Pero volvamos al texto y a Marina después del acto del desnudo. La segunda voz es la que narra y observa que Marina no puede dormir porque está pensando en la acción de Milagros: "La escena te persigue y por más que quieras abreviarla, no puedes, porque se adhiere con obstinación a tu pantalla" (216). Me parece obvio que esta descripción es una indicación del hecho de que Marina se ha excitado sexualmente por Milagros, y yo uno esto a un pasaje anterior del cuento en el cual Marina se ha estado imaginando que Milagros entra en su vida como compañera intelectual. Ambos hechos se narran convenientemente en la segunda persona - unalectora lesbiana puede decir que Marina está fantaseando un estilo de vida lesbiano; una lectora que no sea lesbiana puede percibir esta otra voz como una voz de amonestación. Por medio de esta conveniente técnica de la segunda voz narrativa el texto puede hacer de la lectora una prostituta si sigue la fantasía de Rada sin ver a Marina detrás de la observación de Milagros, o una virgen si sigue la segunda voz como una voz de amonestación -Dios, la iglesia Pentecostal, "la maternidad", y así sucesivamente. De modo que el cuento se presta abiertamente a los críticos/ectores que reducen los cuentos escritos por mujeres puertorriqueñas después de 1970 a la dicotomía de virgen/ prostituta. No obstante, disimuladamente, mediante el uso de esta conveniente técnica, el texto trata de hacer de la lectora lesbiana una pervertida sexual. La lectura de ella quizás sea sólo el producto de su mente homocrítica. Como se diría en Puerto Rico: el escritor del texto ha cubierto todas las bases en su juego de pelota. 
El final del cuento se presenta igual de conveniente. Milagros llega al salón de belleza y le dice a Marina "maquílame en 'shocking red', Marina, y córtame como te dé la gana" (216). Yo como lectora lesbiana, advertí de inmediato que la fantasía de Marina se convertfa en realidad-Milagros le estaba diciendo que hiciera con ella lo que quisiera. Dada la atracción sexual que he notado por parte de Marina hacia Milagros esto sería, como se diría vulgarmente en Puerto Rico, su oportunidad de "meter mano", de tener relaciones con ella. No obstante, si yo hubiera tomado convenientemente la segunda voz como de amonestación, si no hubiera visto a Marina mirando por detrás de Rada y sólo hubiera visto a un hombre que se excitaba ante una mujer, si hubiera tomado la incapacidad de Marina de dormir debido a las imágenes reiteradas del acto de desnudo como indicaciones del temor de Marina de convertirse en una mujer "de la vida" como Milagros, podría decir que Marina está ante una tentación: se le pide que ayude a Milagros a convertirse más en una prostituta dándole "la imagen" y "la apariencia" correspondiente. La segunda voz narrativa termina el cuento con las palabras: "Un temblequeo ... comienza a apoderarse de tus rodillas ... Marina ¿qué responderás?" (217). La pregunta no sólo va dirigida a Marina, sino también a la lectora - ¿qué tipo de lectura ha hecho? ¿Hasta dónde la ha llevado el mercurio de su imaginación?

Vuelvo ahora al artículo de García Ramis, a mi lectura homocrítica y al texto. García Ramis ha dicho que la mujer puertorriqueña ha tenido que adherirse a situaciones sociales, políticas y culturales arcaicas, injustas e injustificables para poder llevar una vida apacible en la isla. Yo añadiría a esto que las escritoras de ficción en Puerto Rico han tenido que hacerle frente a la autorepresión cuando se trata de escribir abiertamente cuentos con/sobre personajes y temas lesbianos. Lo que hacen por lo tanto es dejar los textos con un final abierto, codificado en múl tiples niveles y presentar personajes que usan múltiples máscaras. No obstante, esos textos actúan simplemente como incitaciones para las lectoras lesbianas. Si la lectora homocrítica muerde el anzuelo, el texto puede cerrar conveniente la puerta de su "closet" y dejar a quien hace la crítica afuera sintiéndose como una pervertida sexual y los personajes de adentro como mujeres que hacen actuaciones de desnudo o que tienen una obsesión enfermiza.

En el artículo citado anteriormente de Jean Kennard, ella da como ejemplo de lectura lesbiana, "Vesuvius at home" de Adrienne Rich, sobre la poesía de Emily Dickinson. En ella Rich, como crítica/poeta/lectora lesbiana, se percibe a sí misma como un insecto que revolotea contra las proyecciones de la vida de Emily Dickinson: "Trying to visit, to enter her mind" (Tratando de entrar, de penetrar en su mente). ${ }^{7}$ A pesar de su inteligencia y su perspicacia, a Rich la

\footnotetext{
${ }^{7}$ Adrienne Rich, "Vesuvius at Home: The Power of Emily Dickinson", On Lies, Secrets and Silence (New York: W.W. Norton, 1979) 157-183.
} 
dejan fuera: como lectora lesbiana. Yo, por mi parte, no quiero vivir el resto de mi vida como una versión crítica femenina del peeping Tom, o como un insecto revoloteando. Yo insto a las escritoras de ficción de literatura puertorriqueña a que den paso a su imaginación y libertad a sus plumas para dejar que estos personajes salgan de su encierro de una manera digna. Sólo entonces será que mi lectura como lesbiana no se verá de forma polar ni mi homocrítica se catalogue de extremista en la historia de la crítica de mi patria. Podremos así crear una teoría inclusiva de la producción y la lectura del texto que nos permita expresar e incluir todo lo que llevamos dentro libremente. 